Original Article

\title{
ANTI-OXIDATIVE, ANTI-INFLAMMATORY AND ANTI-ATHEROSCLEROTIC EFFECT OF TAURINE ON HYPERCHOLESTEROLEMIA INDUCED ATHEROSCLEROTIC RATS
}

\author{
HARSHA SHARMA ${ }^{\mathrm{a}^{*}}$, ANKITA JOSHI ${ }^{\mathrm{a}}$, HARSHA LAD ${ }^{\mathrm{a}}$, DEEPAK BHATNAGAR ${ }^{\mathrm{a}}$ \\ aSchool of Biochemistry, Devi Ahilya University, Khandwa Road, Indore 452001, M. P., India \\ Email: harshasharma0102@gmail.com
}

Received: 20 Dec 2017 Revised and Accepted: 01 Feb 2018

\begin{abstract}
Objective: The present study evaluates the antioxidant, anti-inflammatory and anti-atherosclerotic potency of taurine (2-amino ethane sulfonic acid) when administered orally to hypercholesterolemia induced atherosclerotic rats.

Methods: The experimental atherosclerosis was induced by feeding rats with an atherogenic diet comprising of the normal rat chow supplemented with $4 \%$ cholesterol, $1 \%$ cholic acid and $0.5 \%$ thiouracil (CCT diet) for $20 \mathrm{~d}$. Treatment with atorvastatin (10 mg/kg body weight) and taurine ( 2 $\%$ in drinking water) was given to atherosclerotic rats to study antioxidant enzymes (superoxide dismutase, catalase, glutathione-S-transferase), lipid peroxidation in liver, glutathione reductase and protein carbonyl content, extent of DNA damage using the alkaline comet assay, assaying proinflammatory cytokines and quantifying atherosclerotic lesions.
\end{abstract}

Results: Oral supplementation of $2 \%$ taurine to hypercholesterolemic rats modulated antioxidant status and significantly reduced malondialdehyde (MDA) content $(\mathrm{P}<0.05)$. The extent of DNA damage was also significantly reduced as observed by a reduction in the comet tail index $(\mathrm{P}<0.05)$. Taurine exhibited anti-inflammatory activity by significantly inhibiting TNF- $\alpha$ (tumor necrosis factor) and IL-1 $\alpha$ (inter leukine) and also inhibited atherosclerotic lesions by clearing lipid deposits on the intimal surface of the rat aorta.

Conclusion: Oral administration of taurine to rats showed antioxidant and anti-inflammatory activity by modulating oxidants in favor of reducing oxidative stress and also showed anti-atherosclerotic activity in hypercholesterolemia-induced atherosclerosis.

Keywords: Hypercholesterolemia, Anti-inflammatory, Taurine, Anti-atherosclerotic, Antioxidants

(C) 2018 The Authors. Published by Innovare Academic Sciences Pvt Ltd. This is an open access article under the CC BY license (http://creativecommons.org/licenses/by/4.0/) DOI: http://dx.doi.org/10.22159/ijpps.2018v10i3.24372

\section{INTRODUCTION}

One of a major health concern is hypercholesterolemia and is also the main cause of the development of cardiovascular diseases (CVD) [1] Elevated blood lipid levels, such as total cholesterol (TC), triglyceride (TG), and low-density lipoprotein (LDL) and a decrease in high-density lipoprotein (HDL) are directly associated with hyperlipidemia and atherosclerosis [2]. Atherosclerosis is a chronic inflammatory disease, occurring due to prolonged hyperlipidemia. The pathogenesis includes endothelium damage followed by low-density lipoprotein-cholesterol (LDL-C) formation and its oxidation. Due to this monocyte reaching at the site, transform into macrophages and accumulate lipids leading to atherosclerotic plaques in the walls of the arteries. Evidence suggests that progression of atherosclerosis increase the risk of the production of reactive oxygen species (ROS) [3]. Increased ROS production results in oxidative damage to intracellular components. Oxidative damage of cells is protected by various enzymes and non-enzymatic antioxidant defence systems. The focus is being given to various natural dietary components for protecting the cells from these deleterious free radicals.

In the present study, taurine (2-aminoethane sulfonic acid), a free intracellular amino acid was administered orally to rats. Taurine has been reported to regulate oxidative damage [4] and may, therefore, ameliorate prolonged hypercholesterolemia-induced atherosclerosis. Because of the unavailability of literature on the role of taurine in combating hypercholesterolemia induced athero-sclerotic damages, the present study was undertaken. The study included the evaluation of antioxidant enzymes such as superoxide dismutase (SOD), catalase (CAT), glutathione-s-transferase (GST), lipid peroxidation (LPO) glutathione reductase (GSH), protein carbonyl (PCO) content in liver, extent of DNA damage using the alkaline comet assay, assay of pro-inflammatory cytokines and quantifying atherosclerotic lesions in rat feed with high cholesterol diet-induced atherosclerosis.

\section{MATERIALS AND METHODS}

All the chemicals, reagents and organic solvents used in this study were of analytical grade. Taurine, agarose, Na-sarcocinate, triton-X 100, dimethyl sulfoxide (DMSO), 2-thiouracil was procured from Himedia Laboratories Pvt Ltd, Mumbai, India, Atorvastatin tablets were procured from Lupin Pharmaceuticals Limited, Santacruz (East), Mumbai, India. Cholesterol, cholic acid was procured from SD FineChem Ltd. Pyrogallol and hydrogen peroxide were obtained from Merck India Ltd., Mumbai, India. Acetonitrile (ACN), ethylenediamine tetraacetic acid (EDTA) and 1,1,3,3-tetra ethoxy propane (TEP) were procured from Sigma-Aldrich, St. Louis, MO, USA. India. Sudan IV practical grade, streptomycin sulfate, guanidine hydrochloride was obtained from Loba Chemie Pvt. Ltd. Colaba, Mumbai, India. ELISA kits for TNF- $\alpha$ (tumor necrosis factor) and IL (inter leukine)-1 $\alpha$ was purchased from Koma Biotech, Seoul, South Korea.

\section{Animals and diet}

Male albino rats of Wistar strain weighing about $200 \mathrm{~g}$ obtained from the Animal House Facility of DAVV Indore were kept in polypropylene cages (43 x $27 \mathrm{~cm}$ with a floor area of $165.85 \mathrm{~cm}^{2} /$ animal) at an ambient temperature. Animals had free access to feed and water. The rats were acclimatized to the laboratory conditions for $10 \mathrm{~d}$ prior to initiation of the experiment. The experimental protocols were approved by the Institutional Animal Ethics Committee (IAEC) regulations approved by the committee for the purpose of control and supervision of experiments on animals (CPCSEA) (Reg. No. CPCSEA/2015/02 dt.4.7.2015) and conducted humanely.

The animals were divided into four groups of six rats each. Group, I served as the control (cont). Rats in group II, III, and IV were fed with an atherogenic diet comprising of the normal rat chow supplemented with $4 \%$ cholesterol, $1 \%$ cholic acid and $0.5 \%$ thiouracil (CCT diet) [5] for $20 \mathrm{~d}$, Group II rats were hypercholesterolemic, Group III rats received atorvastatin (atorva) 
$(10 \mathrm{mg} / \mathrm{kg})[6]$ and group IV rats received taurine (tau) $(2 \%$ in drinking water) [7] commencing $10 \mathrm{~d}$ after the start of the experimental period. At the end of the $20 \mathrm{~d}$ experimental periods, the blood samples were collected for alkaline comet assay and for detection of pro-inflammatory cytokines. The rats were sacrificed by decapitation and the liver and aortic tissues were quickly excised, washed with saline, blotted dry with a piece of filter paper and a 10 $\%(\mathrm{w} / \mathrm{v})$ homogenate in phosphate buffered saline (PBS) $\mathrm{pH} 7.4$ was prepared to determine antioxidant enzymes and protein content. Sections of aorta were set aside in plaque detection processing.

\section{Estimation of serum cholesterol}

The estimation of serum cholesterol was performed by Sackett's method as described by Varley (1976) [8].

\section{Determination of malondialdehyde levels}

Malondialdehyde (MDA) content in liver was measured by HPLC method [9].

\section{Determination of antioxidant status}

The activity of SOD [10], CAT [11], GST [12], GSH content [13] and PCO [14] in liver tissue were determined.

\section{Alkaline comet assay}

The break in DNA strands in blood leukocytes was measured using single cell gel electrophoresis $[15,16]$. The slides were visualized using a fluorescent microscope (Olympus U-CMAD3) under 10x magnification. The quantification of the DNA strand breaks of the stored images was done using the software Comet score $\mathrm{TM}$ by which tail length, percent DNA in tail, tail moment, and olive moment were obtained directly.

\section{Measurement of proinflammatory cytokines}

Serum proinflammatory cytokines such as TNF- $\alpha$ and IL-1 $\alpha$ were estimated by ELISA kits.

\section{Assessment of atherosclerotic lesions in the aorta}

Assessment of atherosclerotic changes in the aorta was performed by Sudan IV for lipid staining [17]. Photographs of the stained intimal surfaces of the aortas were taken using a digital camera. The digitized images were converted to TIFF file format using the software package Adobe Photoshop CS4 (Adobe Systems Inc, USA). The total and atherosclerotic areas of the intimal surfaces of the aortas were measured in pixels and square inches using NIH Image 1.62. The extent of atherosclerotic lesions was expressed as a percentage of the total intimal surface area.

\section{Statistical analysis}

The data obtained were analyzed by the SPSS software package version 20 . The mean values obtained for the different groups were compared by one-way ANOVA, followed by post hoc-Tukeys (HSD) test and $\mathrm{P}<0.05$ were considered significant.

\section{RESULTS}

\section{Effect of taurine treatment on serum cholesterol}

CCT diet significantly increased serum cholesterol levels in hypercholesterolemic rats (Group II) on day 0,10 and 20 of treatment as compared to control (Group I) (table 1). Treatment with $2 \%$ taurine (Group IV) significantly lowered serum cholesterol on day 20 as compared to Group II.

Table 1: Effect of taurine treatment on serum cholesterol (mg \%)

\begin{tabular}{lccc}
\hline Group & Cholesterol Day 0 & Cholesterol Day 10 & Cholesterol Day 20 \\
\hline I Cont & $81.80 \pm 0.86$ & $84.40 \pm 0.92$ & $89.00 \pm 5.96$ \\
II Hyperchol & $87.40 \pm 0.67^{* *}$ & $199.80 \pm 1.28^{* *}$ & $421.80 \pm 24.59^{* *}$ \\
III Atorva & $86.20 \pm 0.48^{* *}$ & $272.60 \pm 6.96^{* * \# \#}$ & $264.80 \pm 7.08^{* * \# \#}$ \\
IV Tau & $90.60 \pm 0.24^{* *}$ & $218.40 \pm 11.20^{* *}$ & $248.20 \pm 26.10^{* * \# \#}$ \\
\hline
\end{tabular}

Values are mean \pm SEM of 6 animals. The data were analyzed by one-way ANOVA, followed by post hoc-Tukeys $\left(\right.$ HSD) test. ${ }^{*} \mathrm{P}<0.05$; ${ }^{* *} \mathrm{P}<0.01$ as compared to Group I, ${ }^{\mathrm{P}<0.05}$; $\# \mathrm{P}<0.01$ as compared to Group II.

\section{Effect of taurine on atherogenic diet-induced lipid peroxidation in rat liver}

Results showed that LPO in the liver of atherogenic diet-induced hypercholesterolemic rats (Group II) was significantly higher as compared to the control (Group I) (table 2). A significant decrease in liver LPO was observed in rats treated with atorvastatin and taurine (Groups III and IV) as compared to hypercholesterolemic rats (Group II).

\section{Effect of taurine on SOD and CAT activity of rat liver}

The liver SOD activity was significantly decreased in hypercholesterolemic rats (Group II) as compared to control
(Group I). However, treatment with standard drug atorvastatin (Group III) and taurine (Group IV) did not show a significant increase in liver SOD activity as compared to hypercholesterolemic rats (Group II).

The liver CAT activity was significantly decreased in hypercholesterolemic rats (Group II) rats as compared to control (Group I). Treatment with standard drug atorvastatin (Group III) showed a significant increase in the liver CAT as compared to hypercholesterolemic rats (Group II) (table 2). Treatment with taurine (Group IV) however, showed a non-significant increase in CAT activity as compared to hypercholesterolemic rats (Group II).

Table 2: Effect of taurine treatment on LPO and antioxidant enzymes in liver of rats

\begin{tabular}{llll}
\hline Group & $\begin{array}{l}\text { LPO(nmol MDA equivalents formed/mg } \\
\text { protein) }\end{array}$ & $\begin{array}{l}\text { SOD (units/mg } \\
\text { protein) }\end{array}$ & $\begin{array}{l}\text { CAT( } \boldsymbol{\mu m o l ~}_{\mathbf{2}} \mathbf{O}_{2} \text { decomposed/min/mg } \\
\text { protein) }\end{array}$ \\
\hline I Cont & $0.09 \pm 0.01$ & $19.66 \pm 1.14$ & $460.00 \pm 56.36$ \\
II Hyperchol & $0.51 \pm 0.03^{* *}$ & $9.26 \pm 1.05^{* *}$ & $263.20 \pm 9.35^{* *}$ \\
III Atorva & $0.23 \pm 0.01^{* \# \#}$ & $15.12 \pm 0.50$ & $402.40 \pm 23.10^{\#}$ \\
IV Tau & $0.11 \pm 0.02^{\# \#}$ & $9.62 \pm 0.25^{* *}$ & $347.20 \pm 20.74$ \\
\hline
\end{tabular}

Values are mean \pm SEM of 6 animals. ${ }^{*} \mathrm{P}<0.05$; ${ }^{* *} \mathrm{P}<0.01$ significant as compared to Group I. ${ }^{\#} \mathrm{P}<0.05$; \#\# $\mathrm{P}<0.01$ significant as compared to Group II.

\section{Effect of taurine on GST, GSH and PCO content in rat liver}

Liver GST activity was significantly increased in hypercholesterolemic rats (Group II) as compared to control (Group I). Treatment with atorvastatin (Group III) showed a decrease in liver GST as compared to hypercholesterolemic rats (Group II) (table 3). Taurine treatment
(Group IV) however, showed no effect on GST activity in the liver as compared to hypercholesterolemic rats (Group II).

GSH content was found significantly decreased in hypercholesterolemic rats (Group II) as compared to control rats (Group I). Treatment with atorvastatin (Group III) showed no 
significant change in liver GSH as compared to hypercholesterolemic rats (Group II) (table 3). However, a significant increase in liver GSH content was observed with taurine treatment (Group IV) as compared to hypercholesterolemic rats (Group II) (table 3).
PCO content was significantly increased in hypercholesterolemic rats (Group II) as compared to control rats (Group I). Atorvastatin (Group III) and taurine treatment (Group IV) showed no significant change in PCO as compared to hypercholesterolemic rats (Group II).

Table 3: Effect of taurine on GST, GSH and PCO content in rat liver

\begin{tabular}{lllc}
\hline Group & $\begin{array}{l}\text { GST }(\boldsymbol{\mu m o l} \text { GSH conjugated/min/mg } \\
\text { protein) }\end{array}$ & $\begin{array}{l}\text { GSH ( } \boldsymbol{\mu m o l} \text { DTNB conjugated/mg } \\
\text { protein) }\end{array}$ & $\begin{array}{l}\text { PCO(nmol of carbonyl formed/mg } \\
\text { protein) }\end{array}$ \\
\hline I Cont & $1.12 \pm 0.09$ & $34.80 \pm 2.39$ & $0.021 \pm 0.001$ \\
II Hyperchol & $2.10 \pm 0.14^{* *}$ & $15.60 \pm 1.07^{* *}$ & $0.047 \pm 0.004^{* *}$ \\
III Atorva & $1.53 \pm 0.21$ & $18.80 \pm 2.08^{* *}$ & $0.032 \pm 0.001$ \\
IV Tau & $2.16 \pm 0.04^{*}$ & $37.00 \pm 2.82^{\# \#}$ & $0.040 \pm 0.001^{* *}$ \\
\hline
\end{tabular}

Values are mean \pm SEM of 6 animals. ${ }^{*} \mathrm{P}<0.05 ;{ }^{* *} \mathrm{P}<0.01$ significant as compared to Group I. ${ }^{\#} \mathrm{P}<0.05$; \#\# $\mathrm{P}<0.01$ significant as compared to Group II.

\section{DNA damage using single cell gel electrophoresis (comet assay)}

The genoprotective effect of taurine against ROS in peripheral blood leukocytes of hypercholesterolemic rats was evaluated using single cell gel electrophoresis and has been presented in fig. 1 and in table 4. Results indicate that the nuclear DNA was confined to their position in a compact form in the control group (Group I). The hypercholesterolemic group (Group II) showed significantly increased comet parameters such as tail DNA \%, tail length (L), tail moment (TM) and olive tail moment (OTM) as evaluated against control. Atorvastatin treatment (Group III) showed a significant reduction in the comet tail index, tail DNA \%, tail moment and olive tail moment as compared to hypercholesterolemic rats (Group II). Taurine treatment (Group IV) also showed a significant reduction in the comet tail index, tail DNA \%, tail moment and olive tail moment as compared to hypercholesterolemic rats (Group II).
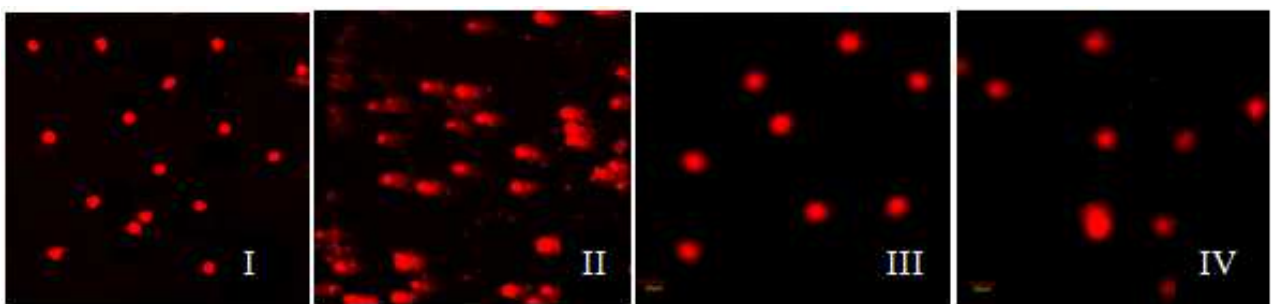

Fig. 1: Effect of taurine treatment on hypercholesterolemia induced DNA damage in peripheral blood leukocytes by comet assay

Table 4: Effect of taurine treatment on hypercholesterolemia induced DNA damage in peripheral blood leukocytes on various comet parameters

\begin{tabular}{|c|c|c|c|c|c|c|c|}
\hline & L Comet $\mu \mathrm{m}$ & L Head $\mu \mathrm{m}$ & L Tail $\mu \mathrm{m}$ & Head DNA \% & Tail DNA \% & $\mathrm{TM} \mu \mathrm{m}$ & OTM $\mu \mathrm{m}$ \\
\hline I Cont & $26.80 \pm 0.80$ & $23.80 \pm 0.80$ & $3.00 \pm 0.00$ & $99.11 \pm 0.29$ & $0.88 \pm 0.29$ & $0.02 \pm 0.01$ & $0.10 \pm 0.03$ \\
\hline II Hyperchol & $58.80 \pm 3.63^{* *}$ & $33.00 \pm 2.75$ & $25.80 \pm 1.68^{* *}$ & $77.54 \pm 0.59^{* *}$ & $22.44 \pm 0.59^{* *}$ & $5.77 \pm 0.36^{* *}$ & $5.21 \pm 0.39^{* *}$ \\
\hline III Atorva & $47.20 \pm 1.65^{*}$ & $42.60 \pm 1.60^{* *}$ & $4.60 \pm 0.50^{* *}$ & $97.43 \pm 0.68^{\# \#}$ & $2.42 \pm 0.62^{\# \#}$ & $0.18 \pm 0.06^{\# \#}$ & $0.46 \pm 0.11^{\# \#}$ \\
\hline IV Tau & $37.60 \pm 2.82^{\#}$ & $33.00 \pm 2.82$ & $4.60 \pm 0.40^{\# \#}$ & $95.46 \pm 0.85^{\# \#}$ & $4.52 \pm 0.85^{\# \#}$ & $0.19 \pm 0.05^{\# \#}$ & $0.52 \pm 0.06^{\# \#}$ \\
\hline
\end{tabular}

Values are mean $\pm \mathrm{SEM}, \mathrm{n}=50, \mathrm{~L}=$ length, ${ }^{*} \mathrm{P}<0.05 ;{ }^{* *} \mathrm{P}<0.01$ significant as compared to Group I. ${ }^{\#} \mathrm{P}<0.05$; ${ }^{\# \#} \mathrm{P}<0.01$ significant as compared to Group II.

\section{Determination of proinflammatory cytokines}

The effect of taurine treatment on serum proinflammatory cytokines such as TNF- $\alpha$ and IL- $1 \alpha$ were evaluated using ELISA method and has been shown in fig. 2. The hypercholesterolemic rats (Group II) showed a significant increase in serum TNF- $\alpha$ and IL- $1 \alpha$ as compared to control (Group I). Treatment with atorvastatin and taurine (Group III and IV) showed significant inhibition of serum TNF- $\alpha$ and IL-1 $\alpha$ as compared to hypercholesterolemic animals (Group II).

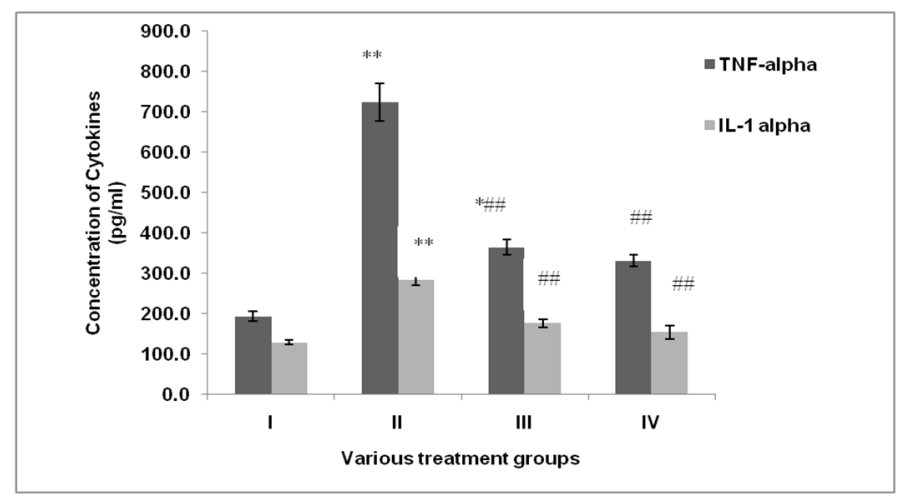

Fig. 2: Effect of taurine treatment on serum pro-inflammatory cytokines, values are mean $\pm S E M, n=6 .{ }^{*} P<0.05 ;{ }^{* *} P<0.01$ significant as compared to group I, ${ }^{\#} \mathbf{P}<0.05 ;{ }^{\# \#} \mathrm{P}<0.01$ significant as compared to group II 


\section{Atherosclerotic lesions in the aorta}

A representative photograph of atherosclerotic changes in the internal surfaces of aortas from the four groups of rats, stained with Sudan IV is shown in fig. 3 and the extent of atherosclerotic lesions in these groups is summarized in fig. 4. There were no athero- sclerotic lesions in the aortas of Group I. However, significant areas of the intimal surfaces of aortas from Group II were covered with atherosclerotic plaques.

Group III and Group IV showed a very low amount of atherosclerotic plaques, indicating recovery after treatment in these groups.

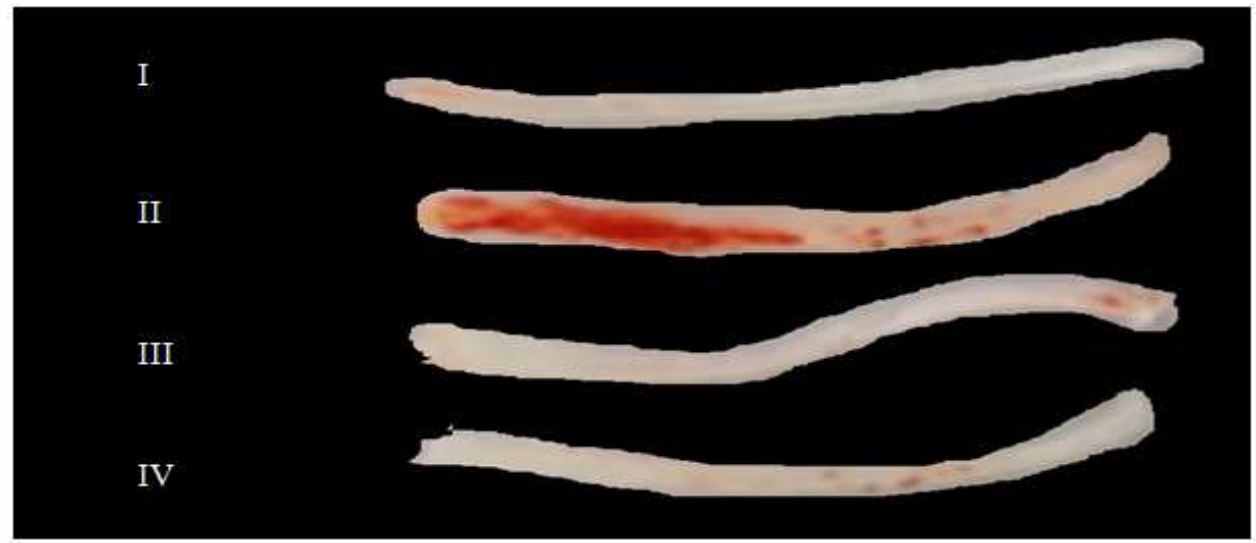

Fig. 3: Representative photographs of the intimal surfaces of aortas of the four groups, stained with sudan IV. The lipid deposits on the internal surfaces of the aortas are shown in brick red color

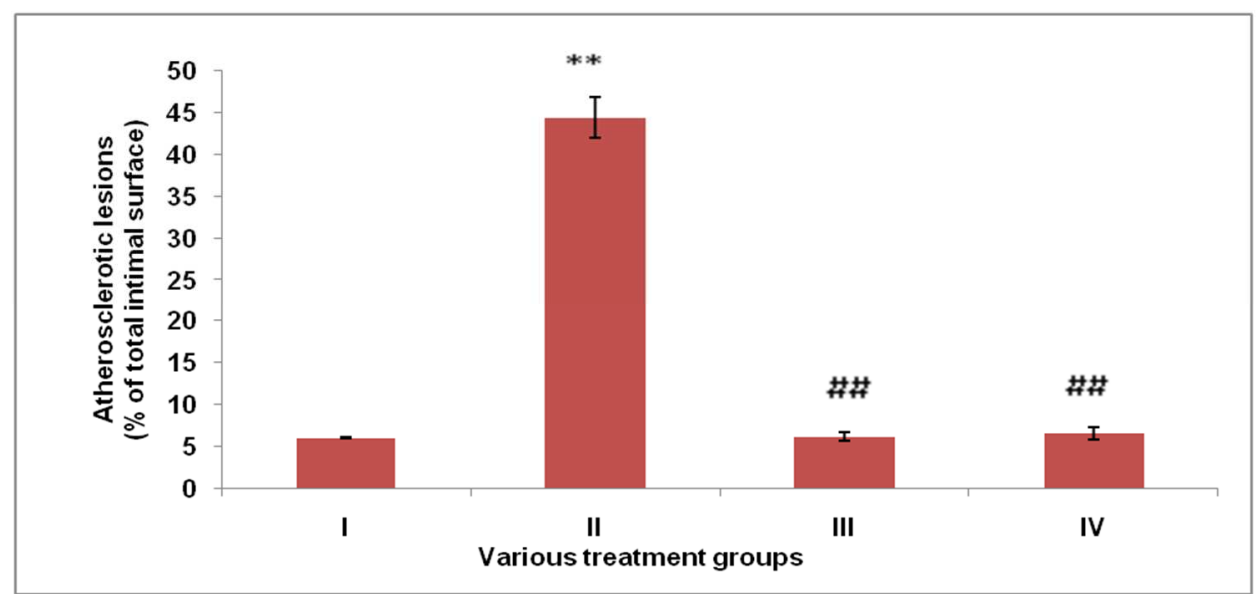

Fig. 4: Quantification of plaque deposition on intimal surfaces of aorta, Values are mean $\pm S E M, n=6 .{ }^{*} P<0.05 ;{ }^{* *} P<0.01=\operatorname{significant~as~}$ compared to Group I and ${ }^{\#} \mathbf{P}<0.05 ;{ }^{\# \#} \mathbf{P}<0.01=$ significant as compared to group II

\section{DISCUSSION}

Studies have shown that elevated serum TC and LDL-C concentrations, promote atherosclerosis and cardiovascular complications [18]. Oxidative modification of LDL-C has been shown to initiate the progression of atherogenic changes in aorta $[3,19]$. This has prompted the study of antioxidants in the prevention and progression of CVD.

The results show that hypercholesterolemia leads to increase in tissue LPO. Similar findings were also observed in other studies [20, 21]. The increase in liver LPO in the hypercholesterolemic group as compared to control was due to increased oxidative stress and cellular damage. However, the decrease in LPO observed in taurinetreated animals, suggest that taurine strengthen the antioxidant defence system and prepared the animals to withstand the damaging effects of hyperlipidemic state. The decrease in cholesterol content along with its LDL fraction could also be due to increased cholesterol excretion and decreased cholesterol absorption through the gastrointestinal tract [22]. The decrease in liver SOD, CAT and GSH content in hypercholesterolemic rats was probably due to free radicals induced inhibition of antioxidant enzymes in high cholesterol-fed animals.
The GSH content significantly decreased in the liver of animals fed high-cholesterol diet as compared to the control diet group indicating oxidative stress due to CCT diet. This observation is consistent with the administration of high cholesterol in experimental rats [23]. A significant increase in GSH content in taurine administered rats suggests that taurine facilitates the removal of free radicals and may enhance the repairing of the endogenous antioxidant system due to oxidative stress.

Protein carbonyl is the widely used biomarker for oxidative damage to proteins by various ROS [24]. Studies have suggested that the accumulation of oxidized proteins is associated with progression of atherosclerosis [25]. However, in the present study, no significant change was observed in liver PCO content with the taurine administration in hypercholesterolemic rats.

Lymphocyte DNA damage is also one of the reliable markers to detect oxidative stress [26, 27]. It has been shown that increased DNA damage in hypercholesterolemia was caused by the increased production of ROS and decreased antioxidative capacity [28], which ultimately leads to the significant development and the progression of atherosclerosis $[29,30]$. The present study showed the primary DNA damage in leukocytes of atherosclerotic animals. 
Administration of taurine conferred significant protection against lymphocyte DNA damage, may be due to its free radical scavenging activity.

Pro-inflammatory cytokines such as TNF- $\alpha$ and IL- 6 are considered good predictors of CVD [31]. In the present investigation, high-fat diet-induced hypercholesterolemic animals showed increased levels of serum proinflammatory cytokines such as TNF- $\alpha$ and IL- $1 \alpha$ Taurine significantly reduces the serum concentration of these cytokines, indicating the anti-inflammatory property of taurine. The studies reviewed by Berg and Scherer have demonstrated that increase in the inflammatory markers such as IL- 6 and TNF- $\alpha$ may translate to accelerated atherogenesis [32]. Induction of these cytokine gene expressions is regulated by a common pathway, ie, activation of nuclear factor- $\kappa B(N F-\kappa B)$ signalling $[33,34]$. Studies have shown that taurine chloramines inhibit inflammatory responses within the atherosclerotic lesions by inhibiting NF- $\mathrm{BB}$ activity in vascular smooth muscle cells and mononuclear cells [35]. Other studies also indicate that taurine treatment significantly reduced atherosclerotic lesions in the aorta of hypercholesterolemic rats [36]. It is proposed that recovery in atherosclerosis by taurine in rats may be related to the antioxidative and the DNA repair properties of taurine.

\section{CONCLUSION}

The current investigation focuses on the role of administration of taurine as a potent antioxidant, as indicated by the preventive action of lipids and protein oxidation, increase in liver GSH content and reduced DNA damage. The anti-inflammatory and antiatherosclerotic potential has been suggested to be attributed due to the antioxidant action of taurine.

\section{ACKNOWLEDGEMENT}

The authors thank Scientist Incharge, sophisticated instrument centre (SIC), Indian Institute of Technology, Indore for providing Fluorescence microscopy facility.

\section{AUTHORS' CONTRIBUTIONS}

Harsha Sharma conducted the experiments and also prepared the manuscript. Ankita Joshi partly conducted the experiments and also helped in manuscript writing. Harsha Lad helped in the planning of experiments. Deepak Bhatnagar was involved in the planning of experiments and in assisting the manuscript writing. All authors have read and approved the content of the manuscript.

\section{CONFLICT OF INTERESTS}

The authors declare that there are no conflicts of interest

\section{REFERENCES}

1. Raida K, Nizar A, Barakat S. The effect of Crataegus aronica aqueous extract in rabbits fed with high cholesterol diet. Eur J Sci Res 2008;22:352-60.

2. Lee MK, Park YB, Moon SS. Hypocholesterolemic and antioxidant properties of 3-(4hydroxyl) propanoic acid derivatives in high-cholesterol-fed rats. Chem Biol Interactions 2007;1:9-19.

3. Vogiatzi G, Tousoulis D, Stefanadis C. The role of oxidative stress in atherosclerosis. Hellenic J Cardiol 2009;50:402-9.

4. Aruoma OI, Halliwell B, Hoey BM, Butler J. The antioxidant action of taurine, hypotaurine and their metabolic precursors. Biochem J 1988;256:251-5.

5. Kritchevsky D. Experimental atherosclerosis in primates and other species. Annals New York Academy Sci 1969;162:80-8.

6. Srinivas M, Annapurna A, Reddy YN. Anti-atherosclerotic effect of atorvastatin and clopidogrel alone and in combination in rats. Indian J Exp Biol 2008;46:698-703.

7. Nandhini AT, Balakrishnan SD, Anuradha CV. The response of the liver antioxidant system to taurine in rats fed high fructose diet. Indian J Exp Biol 2002;40:1016-9.

8. Varley H. Practical Biochemistry. 4th ed. New Delhi (Indian): Amold Heinemann Publishers; 1976.

9. Tukozkan N, Erdamar H, Seven I. Measurement of total malondialdehyde in plasma and tissue by high-performance liquid chromatography and thiobarbituric acid assay. Firat Tip Dergisi 2006;11:88-92.

10. Marklund S, Marklund G. Involvement of the superoxide anion radical in the autooxidation of pyrogallol and convenient assay for superoxide dismutase. Eur J Biochem 1974;47:469-74.

11. Aebi H. Catalase. In: Bergmeyer HU. editor. Methods in an enzymatic assay. New York: Academic Press; 1983. p. 276-86.

12. Habig WH, Pabst MJ, Jacoby WB. Glutathione-S-transferases, the first enzymatic step in mercapturic acid formation. J Biol Chem 1974;249:7130-9.

13. Beutler E, Duron O, Kelly BM. Improved methods for the determination of blood glutathione. J Lab Clin Med 1963;61:882-8.

14. Levine RL, Garland D, Oliver CN, Amici A, Climent I, Lenz A, et al. Determination of carbonyl content in oxidatively modified proteins. Methods Enzymol 1990;186:464-78.

15. Gandhi NM, Nair CKK. Radiation protection by Terminalia chebula: some mechanistic aspects. Mol Cell Biochem 2005;277:43-8

16. Benkovic V, Knezevic AH, Dikic D, Lisicic D, Orsolic N, Basic I, et al. Radioprotective effects of propolis and quercetin in gammairradiated mice evaluated by alkaline comet assay. Phytomedicine 2008;15:85-8.

17. Holman RL, McGill HC Jr, Strong JP, Geer JC. Techniques for studying atherosclerotic lesions. Lab Invest 1958;7:42-7.

18. Dominiczak MH. Hyperlipidemia and cardiovascular disease. Curr Opin Lipidol 1998;9:609-11.

19. Esterbauer $\mathrm{H}$, Wag G, Puhl H. Lipid peroxidation and its role in atherosclerosis. Brit Med Bull 1993;49,566-76.

20. Fong LG, Steiberg D. Oxidatively modified low-density lipoproteins: A potential role in recruitment and retention of monocyte/macrophages during atherogenesis. Proc Natl Acad Sci USA 1987;84:2995-8.

21. Kumar N, Kar A. Ameliorating effects of pyrroloquinoline quinone (PQQ) on PTU induced oxidative damage in mice kidney. Asian J Pharm Clin Res 2014;7:121-6.

22. Mishra R, Karmarkar SM, Bhagwat AM. Preliminary dose dependent study on antihyperlipidemic activity of Hibiscus rosa sinensis Linn leaves on triton WR 1339 induced hyperlipidemic mice model. Asian J Pharm Clin Res 2011;4:100-2.

23. Cui BK, Liu S, Lin XJ, Wang J, Li SH, Wang QB et al. Effects of Lycium barbarum aqueous and ethanol extracts on high fat-diet induced oxidative stress in rat liver tissue. Molecules 2011;16:9116-28.

24. Dalle-Donne I, Rossi R, Colombo R, Giustarini D, Milzani A. Biomarkers of oxidative damage in human disease.Clin Chem 2006;52:601-23.

25. Stadtman ER, Levine RL. Free radical-mediated oxidation of free amino acids and amino acid residues in proteins. Amino Acids 2003;25:207-18.

26. Collins AR, Dusinska M, Gedik CM, Stetina R. Oxidative damage to DNA: do we have a reliable biomarker? Environ Health Perspect 1996;04 Suppl 3:465-69.

27. Gedik CM, Wood SG, Collins AR. Measuring oxidative damage to DNA; HPLC and the comet assay compared. Free Radic Res 1998;29:609-15.

28. Harangi M, Remenyik E, Seres I, Varga Z, Katona E, Paragh G. Determination of DNA damage induced by oxidative stress in hyperlipidemic patients. Mutat Res 2001;513:1725.

29. Andreassi MG. Coronary atherosclerosis and somatic mutations: an overview of the contributive factors for oxidative DNA damage. Mutat Res 2003;543:67-86.

30. Kamesh V, Sumathi T. Effect of Bacopa monniera Linn. in attenuating hepatic oxidative stress in hypercholesterolemic induced rats. Asian J Pharm Clin Res 2012;5:90-5.

31. Morrow DA, Ridker PM. C-reactive protein, inflammation, and coronary risk. Med Clin North Am 2000;84:149-61.

32. Berg AH, Scherer PE. Adipose tissue, inflammation, and cardiovascular disease. Circ Res 2005;96:939-49.

33. Barnes PJ, Karin M. Nuclear factor-kappa B: a pivotal transcription factor in chronic inflammatory diseases. N Engl J Med 1997;336:1066-71. 
34. Hajra L, Evans AI, Chen M. The NF-kappa B signal transduction pathway in aortic endothelial cells is primed for activation in regions predisposed to atherosclerotic lesion formation. Proc Natl Acad Sci USA 2000;97:9052-7.

35. Sethupathy S, Elanchezhiyan C, Vasudevan K Kim H, Jeon H, Kong H, Yang Y, Choi B, Kim YM, et al. A molecular mechanism for the anti-inflammatory effect of taurineconjugated 5-aminosalicylic acid in inflamed colo. Mol Pharmacol 2006;69:1405-12.

36. Rajagopal G. Antiatherogenic effect of taurine in high fat diet fed rats. Indian J Exp Biol 2002;40:1169-72. 